\title{
6. PATIENT'S RIGHTS IN THE CONTEXT OF A PANDEMIC - ANALYSIS OF THE SITUATION IN PORTUGAL
}

André Dias Pereira, Ana Elisabete Ferreira and Carla Barbosa

\section{Introduction}

At the beginning of 2020, it was unimaginable that we would be faced with the challenges brought by the emergence and evolution of the Covid 19 pandemic. Attempting to react to the most urgent needs first, government entities relied on legally established instruments that allow the government to adopt exceptional emergency measures that would otherwise be beyond limits of the law. The Constitution of the Portuguese Republic allows a state of emergency to be declared in cases of effective or imminent aggression by foreign forces; serious threats or disturbances to the democratic constitutional order; or situations of public calamity. Without question, Covid19 is a public calamity justifying emergency measures.

Decrees pertaining to the state of emergency are nonetheless limited because the emergency laws must not negatively impact the right to life, personal integrity, personal identity, civil capacity, and citizenship. Emergency new criminal law cannot be retroactive, and previous guarantees of defence for defendants and freedom of conscience and religion remain in place. At the same time, the Portuguese Constitution of 1976 proclaimed the right of citizens to health protection through "the creation of a universal and free National Health Service" (art. 64) and, in 1979 , Law no. 56/79, of September $15^{\text {th }}$, creates the National 
Health Service (in Portuguese, SNS, Sistema Nacional de Saúde) as a universal and general health system, free of charge.

Therefore, it is important to examine how lawful measures adopted in response to the pandemic impact the rights of patients, whose rights are in principle, part of a rubric that cannot be undermined during the pandemic emergency.

\section{a) Statistics About the Portuguese Health Care System}

It is empirically proven that Portugal has a high standard of healthcare. In 2018, the Portuguese health system ranked in $13^{\text {th }}$ place, in the Euro Health Consumer Index (EHCI), rising seven positions in comparison to 2015 (and definitively improved from $25^{\text {th }}$ place, its previous position in 2012). For the first time, Portugal ranked above the United Kingdom and Spain. Portugal performed particularly well in quality-price ratings. In the World Health Report, organized by the World Health Organization, published in 2020, with data from 2019, Portugal ranks $12^{\text {th }}$ worldwide ${ }^{1}$. According to data from the Statistics Database Pordata Portugal spends about 9.5\% of its GDP on health care in 2019. In 2019, according to the European Observatory of Health Systems and Policies, Portugal spent EUR 2029 per capita on health care, which corresponds to 9\% of GDP and represents a third less than the EU average (EUR 2884) despite an increase in health expenditures compared to the period of economic crisis in 2017. Direct payments have grown to become the second largest source of revenue, reaching $27.5 \%$ of total health expenditures. Capacity building primary care, required the Government to adopt measures to increase the number of general practitioners for the National Health Service, thus increasing the number of users with access to general practitioners and family doctors. Municipalities were thereby granted a more relevant and interventional role in the management of primary health care ${ }^{2}$. According to 2019 data from the OECD Observatory, Portugal's health profile demonstrates effectiveness in the treatment of chronic

1 Full Report and Statistic Tables available at: https://www.who.int/data/gho/ publications/world-health-statistics

2 Report available at: https:/ec.europa.eu/health/sites/health/files/state/docs/ 2019_chp_pt_english.pdf 
pathologies by primary and outpatient care, with avoidable admission rates well below the European average, and has a high performance in the treatment of certain diseases, such as cancer, registering survival rates above the other member states. Unfortunately, the greatest weaknesses within the Portuguese system represent constant unmet needs in key areas in the last five years: the country must reduce socioeconomic and gender disparities in order to: ameliorate the health profile of its citizens; lessen the impact of risk factors such as obesity and behavioural factors (such as excessive alcohol and tobacco consumption); e reduce the time for waiting lists for scheduled appointments and surgery; and this in turn will offer better and more intense allocation of human resources.

Design of the health policy in the late 1980s reshaped health care in Portugal by introducing neoliberalism and applying it by opening up the health care infrastructure to the market economy. A revision of the Constitution, in 1989, eliminated total gratuitousness, admitting an SNS which "tends to be free". The Lei de Bases da Saúde (Framework Law on Healthcare) was reformulated in $1990^{3}$ providing greater openness to the private health market. Yet, the fundamental structure of the SNS, the system based on publicly provided health care remained in force, complemented by an increase in the access to consultations in private offices and out-of-pocket payments.

Since 2000, there has been a marked emergence of strong private health corporations that base their billing largely on private insurance (health plans) purchased by companies and families, in ADSE (public health plan limited to workers in public functions) and other health subsystems and services of the SIGIC system (an integrated management system for surgery candidates - Sistema Integrado de Gestão de Inscritos para Cirurgia, in Portuguese), designed to shorten waiting lists for surgery. Many of these companies are foreign. The combined system incorporates different payment models: (1). the National Health Service (SNS) financed through the annual State Budget; (2) social insurance, financed by professionally funded health funds; and (3) individually funded voluntary insurance and a model based on direct

3 Version repealed by Law no. 95/2019, of 4 September which approves the Basic Law of Health and repeals Law no. 48/90, of 24 August, and Decree-Law no. $185 / 2002$, of August 20. 
payments ${ }^{4}$. This hybrid character of the Portuguese health system reflects a strong presence of the public system (SNS), even though more than $20 \%$ of the population pays for private and social systems. The Portuguese health system is therefore characterized by three coexisting and overlapping systems: (1) universal SNS; (2) special health insurance schemes for certain professions or sectors (such as civil servants, banks and insurance companies' employees), known as health subsystems; and (3) private voluntary health insurance. The Portuguese health system therefore mixes public, private and social providers.

The universal nature of the SNS makes it especially important. A policy goal to improve efficiency and effectiveness of the SNS is the underpinning for a wide range of measures and reforms, implemented in recent years. The Ministry of Health, responsible for allocating resources to the SNS, ensures that the overall budget for the SNS is distributed among various institutions, based on past expenses. More recently, payment methods have been introduced to cover the general costs of some pathologies. Oncology has its own model of care, consisting of three highly specialized centers (Institutos Portugueses de Oncologia Francisco Gentil, known as IPO), located in the cities of Lisbon, Porto and Coimbra, which cover the whole territory, complemented by care provided in general hospitals.

Continuous Care and Palliative Care providers are also organized in specific networks, articulated between the Ministries of Health and Social Security, and with a very important impetus from the social sector of health, in particular from the IPSS's (private institutions for social solidarity, in Portuguese, Instituiçôes Particulares de Solidariedade Social) and of the Misericórdias (Houses of Mercy).

\section{b) Health Democracy: Patient Participation in Health Decisions}

Unlike other European countries, Portuguese patients do not usually hold a seat on the board of directors or management of hospitals, usually comprised of health professionals and management professionals. Health democracy and the relaxation of the doctor-patient relationship

${ }^{4}$ On the Portuguese Healthcare System see Jorge Simốes/António Correia DE Campo, O Percurso da Saúde: Portugal na Europa, Almedina, 2011. 
are thus impaired, a reality only diminished by the fact that patients form private associations that promote dialogue with health entities.

There is vast international evidence supporting the importance of democratic operability and representation in health management. Several international organizations and entities, including the European $\mathrm{Pa}$ tients 'Forum (EPF), the World Health Organization (WHO) and the Organization for Economic Cooperation and Development (OECD) advocate public participation in the field of health. Since 2002, reform laws in France have effectively operationalized a response to these challenges for stakeholders, by placing emphasis from the standpoint of démocratie sanitaire, by giving high priority to the collective powers of patients. Indeed, article L1114-1 of the French Public Health Code has come to provide, inter alia, that associations, when regularly constituted, with an activity in the field of health quality and patient care, can be approved by the competent administrative authority at the regional or national levels to represent users, concerning decisions about the direction or administration of health units, or public health authorities. Patient representatives are entitled to training, in order to facilitate the exercise of this mandate. Note that this goes beyond a purely consultative role: in reality, this role involves actively participating (on an equal footing to managers directors and administrators) when defining the system. This approach ensures effective participation of patients in health management, by empowering them.

Associations and non -governmental informal groups of stakeholders that seek to represent and participate in health policy decisions are entitled to broad support across our legal system. The Lei de Bases da Saúde (Law no. 95/2019), in accordance with the Constitution, expressly sets out the right of citizens to intervene in health decision-making and the participatory management of the SNS institutions. Yet, in Portugal, there has not been a specific and concrete concern within the legal system regarding this issue. Until recently, there was not a clear role for patients in the management and administration of health services, nor in the institutional framework for training health professionals. The Charter for Public Participation in Health (Carta para a Participação Pública em Saúde), approved by Law no. 108/2019, of September $9^{\text {th }}$, intended to change situation. Adopted with objectives of encouraging: participation by people, ill or not, and their representatives regarding decision making affecting the health of the 
population; decision making in health based on broad public participation; consolidation of public participation at the policymaking level and within different organs and entities of the State, the law mandates deepening the existing participation processes and the creation of new spaces and participatory mechanisms $s^{5}$ in Portugal.

It remains to be verified and established whether existing mechanisms for enhancing participation by patients and their representatives are aligned with the international norms for health democracy, and to identify their impacts on health policies. According to the Charter, public participation of people with or without disease and their representatives covers, inter alia, the following areas: National Health plan and health programs; SNS management (including human, material and financial resources, and the organization of health care provision, through the grouping of health centres and hospitals); state budget for health; health technology assessment; health quality assessment; standards and guidelines; health ethics and research; rights of people with or without disease and their representatives.

When balancing the structural features of health democracy (which provide support to individual decision-making and empower patients, by ensuring veritable respect for the right to information and for the right of access and control of individual patient health information), once the collective dimension is reinforced, then there must be a

5 The Charter for Public Participation in Health contributes to: promoting and defending the rights of people with or without disease, especially with regard to the protection of health, information and participation; inform public authorities about the priorities, needs and concerns of people with or without disease and their representatives; make health policies more effective and, consequently, achieve better health outcomes; promote the transparency of decisions and accountability by those who decide; bring the State and civil society closer together, deepening the dialogue and regular interaction between the two; legitimize decisions about cost-effectiveness assessment and ethical dilemmas posed by technological innovations.

Public participation in health must be based on the following principles: recognition of public participation as a right of people with or without disease and their representatives; recognition of people with or without disease and their representatives as partners in decision-making processes; recognition of the importance of the specific knowledge and experience of the person with or without illness; autonomy and independence of people with or without disease and their representatives in the proceedings; transparency and public disclosure of participatory processes; creation of the necessary conditions for participation; complementarity and integration between institutions and mechanisms of representative democracy and participatory democracy. 
structural counterweight in order to preserve effective patients' rights. This can be achieved by creating and legitimizing patient associations and NGOs, in the hope of strengthening civil society.

\section{c) Global Pandemic: Gamechanger for systemic solutions and omissions}

Two key dimensions of the Portuguese health system were severely impoverished by the pandemic. - 1) the quality of health care delivery and 2) promotion of patient participation in health policies and decisions.

The SNS has significantly increased its capacity to provide health care, increasing and continuing to increase, by the hundreds, the number of beds, health professionals, supplementary means of diagnosis, therapy and medical devices, in an unparalleled growth. The response offered by the SNS proved to be quite robust - in speed, adequacy, quality and quantity. We believe that the public response was robust compared to any possible private response in the same context, given the demands for rapid decision making and coordination that were necessary during pandemic peaks. Yet, weaknesses in the system were accentuated due to the lack of available resources (human or equipment resources,) which become scarce while demand continued to rise.

\section{Testing}

Regarding testing, the Ministry of Health organized and monitored the implementation of a system of tests, free of charge for each user, within the framework of indications of the General Directorate of Health (Direção Geral da Saúde, DGS). Tests were available for anyone who developed a clinical presentation suggesting the diagnosis of an acute respiratory infection with at least one of the following symptoms: persistent coughing, worsening of the usual coughing symptoms or coughing associated with headache or myalgia; or fever (temperature $\geq 38.0^{\circ} \mathrm{C}$ without another attributable cause), or breathing difficulty/dyspnoea, without another attributable cause total; or partial loss of smell (anosmia), weakened taste (ageusia) and sudden onset or decreased taste (dysgeusia). All these categories of symptoms were considered suspected cases of infection by COVID-19, and were indicated for testing (free), in reference centres. 
A majority of this monitoring is carried out by Linha Saude 24 (a telephone hotline, known as SNS24), through which all citizens can obtain information on the proper way to handle their situation. The laboratory test for SARS-CoV-2 may be ordered by the family health unit (USF) team doctor / personalized health care unit (UCSP) for patients with indication for clinical surveillance and isolation at home (process which guarantees that the test is performed free of charge). It may also be requested remotely through the Exames Sem Papel online platform, by the doctor of the ADR-C teams (areas dedicated to respiratory patients in primary health care) or ADR-SU (areas dedicated to respiratory patients in hospital units) or by any doctor who, during the clinical evaluation, suspects a COVID-19 infection. SNS24 health professionals who perform clinical screening, may, exceptionally and automatically, also generate a test request, by applying an algorithm approved by the DGS.

The reference test for the diagnosis of COVID-19 is the Molecular Nucleic Acid Amplification Test (TAAN). During an outbreak however, rapid antigen tests are used to reduce the time needed for results in order to implement the necessary measures. The tests used in Portugal are those recommended by international health authorities, either by the European Centre for Disease Control (ECDC) or by the World Health Organization (WHO).

Patients without symptoms of COVID-19 do not, in principle, have an express indication to take the free test, according to the protocol issued by the DGS. They may be tested by their own initiative or within the institutions where they usually provide their professional activity, if those promote screening. Within the private health sector, there is a wide offering of testing, with different available procedures and prices ${ }^{6}$.

\section{Treatment}

Within the SNS, the treatment for COVID-19 is free. Hospitalization, supplementary diagnosis testing and therapy in hospitals are universal and free. When there is no need for hospitalization, medication acquired at a community pharmacy respect the general and special regimes of participation by the State in the price of medicines.

6 Please note only that these guidelines are subject to recurring updates. 
Considering the scarcity of SNS resources, the treatment of some patients which, in a normal situation, would be monitored within the scope of the SNS was contracted with private hospital units.

\section{Vaccination}

Regarding vaccination, there is legal decision to vaccinate the entire Portuguese population completely free of charge, as long as they are eligible according to the clinical indications approved for each vaccine in the European Union. Priority groups were defined, in order to reach more vulnerable populations who are prone to COVID-19 infection. According to the established vaccination plan, which may change due to the evolution of scientific knowledge and the indications and contraindications that may be approved by the European Medicines Agency, the vaccination strategy will be as follows: ${ }^{7}$

Phase 1, from December 2020:

- Health professionals involved in providing care to patients

- Professionals in the armed forces, security forces and critical services

- Professionals and residents in Elderly Residential Homes (ERPI, Estruturas Residenciais para Pessoas Idosas) and similar institutions

- Professionals and users of the National Integrated Continuing Care Network (RNCCI, Rede Nacional de Cuidados Continuados)

From February 2021:

- Individuals over $80 .^{8}$

- Aged 50 or above, diagnosed with one of the following pathologies:

- Cardiac Insufficiency;

- Coronary Disease;

7 See: https://covid19.min-saude.pt/vacinacao/. However, new groups of people were added as priorities and, therefore, were included in Phase 1 of the vaccination..

8 On this matter, the active participation of citizens (including Professor André Dias Pereira) defending the widening the established priorities to include individuals over 80 years old was decisive: Carta Aberta sobre os critérios para vacinação prioritária no Plano de Vacinação contra a covid-1, in Público, 26 de janeiro de 2021: https://www. publico.pt/2021/01/26/sociedade/opiniao/carta-aberta-criterios-vacinacao-prioritaria-plano-vacinacao-covid19-1947843 
- Renal insufficiency;

- Chronic respiratory disease with ventilator support and/or long-term oxygen therapy.

Phase 2, from April 2021:

- People 65 years and older (who have not been previously vaccinated)

- People between 50 and 64 years of age, with at least one of the following pathologies:

- Diabetes;

- Active malignant neoplasm;

- Chronic kidney disease;

- Liver failure;

- Arterial hypertension;

- Obesity;

- Other pathologies with less prevalence that may be later defined, depending on scientific knowledge.

Phase 3, date to be determined, following conclusion of Phase 2:

- All other eligible population, within which priorities may equally be determined.

\section{d) Articulation between the Health System and the Social Security System}

The pandemic crisis has serious socio-economic consequences, decreasing household productivity and income, and increasing unemployment and daily expenses. Portugal created a set of «ad hoc» support to minimize these effects.

\section{For employers:}

Through Social Security, the following employment support measures were created for employers:

- Simplified Layoff (Extraordinary Measure to Support the Maintenance of Employment Contracts)

- Support to Progressively Resume Activity (Extraordinary Support to Progressively Resume Activity) 
In the first quarter of 2021, employers benefit from the suspension of foreclosures for social security debts and the suspension of ongoing benefit plans. They also benefit from the deferral of contributory obligations for the months of November and December 2020.

\section{Salaried Employees}

Through Social Security, employees, (including members of statutory bodies and domestic service workers, maintain access to extraordinary social protection measures:

- Disease Allowance for Prophylactic Isolation

- Covid-19 sickness benefit

- Covid-19 sickness allowance for Health Sector workers

- Assistance to child or grandchild by Prophylactic Isolation

The measure for Child or Grandchild Assistance for Prophylactic Isolation is applicable to workers who cannot perform their activity, when they are assisting children or other dependents, under 12 years of age, or disabled and chronic illness sufferers regardless of age, in situation of prophylactic isolation (certified by the Health Delegate) or when they are infected by COVID-19. Citizens are entitled to childcare allowance, in an amount corresponding to $100 \%$ of the net reference remuneration, with a minimum limit of $65 \%$ of the gross remuneration. This value has been in effect since April 1, 2020.

For people seeking assistance for a grandchild, the amount of the subsidy corresponds to $65 \%$ of the reference remuneration. The net reference remuneration value is obtained by deducting the contributory rate applicable to the beneficiary and the personal income tax (IRS) retention rate from the gross amount of the reference remuneration.

Large-scale communication work was also carried out to inform workers about their social rights.

\section{Self-employed Workers}

Self-employed workers, including individual entrepreneurs (who were subject to suspended activities or closure of facilities and establishments during the emergency by legislative or administrative determination), were supported by several measures:

- Extraordinary support to reduce the economic activity of self-employed workers 
- Extraordinary Measure of Incentive to Professional Activity

- Support for Social Disprotection

\section{Social and Health Institutions}

Through the IEFP - Institute of Employment and Professional Training, Instituto do Emprego e da Formação Profissional - the Support Program for the Emergency Reinforcement of Social and Health Equipment (Programa de Apoio ao Reforço de Emergência de Equipamentos Sociais e de Saude) was created, with the Emergency Reinforcement of Social and Health Equipment (MAREES - Reforço de Emergência de Equipamentos Sociais e de Saúde), a temporary and exceptional measure, which consists of supporting the performance of socially necessary work, to ensure the responsiveness of public institutions and the solidarity sector with activity in the social and health area, during the COVID-19 disease pandemic.

This measure aimed to contribute to ensuring the responsiveness of public institutions and the solidarity sector with activity in the social and health area, namely health services, hospitals, homes or residential homes for the elderly and people with disabilities; promote the employment, by preserving and improving the socio-professional skills of the unemployed (through maintaining contact with the labour market and striving to improve the earnings of the unemployed or of workers with a suspended employment contract, working reduced hours or employed part-time).

The measure is aimed at unemployed people with or without unemployment benefits), workers with a suspended work contract, workers who had reduced hours, or were employed part-time. It also covers students, in higher education, and trainees, aged no less than 18 years.

\section{e) Impacts on Patients' Rights}

During the pandemic, the Government, through the Ministry of Health, issued Guidelines to suspend scheduled and non-priority activity. The last of these decrees, Order no. 574-A/2021, currently in force, determines that hospital establishments of SNS must up their Contingency Plans to the maximum level and suspend the programmed non-urgent assistance activity that can revert in reinforcing care for 
critically ill patients. This measure is justified by the emergence and spread of the SARS-CoV-2 virus in Portugal, which determined the need to ensure the prevention, containment, mitigation and treatment of COVID-19, through the adoption of a set of exceptional and temporary response measures to the pandemic.

In January 2021, the date of publication of the referred decree, Portugal registered a rate of over 900 cases per 100000 inhabitants and an average number of secondary cases resulting from an infected case, measured as a function of time, $\mathrm{R}(\mathrm{t})$, greater than 1 (the rate refers to the accumulated infections of the previous 14 days).

These factors put the health system and the SNS in particular, under extreme pressure, especially considering hospitalization rates (hospitalization in infirmary and hospitalization in intensive care, both with occupancy rates, in January, which are situated between $85 \%$ and $96 \%$ ). In January 2021, the number of hospitalizations for COVID-19 in SNS institutions peaked. Imposing a strict lockdown in February and March may control the pandemic and thereby safeguard public health.

Health resources allocation guidelines were published, considering the current epidemiological circumstances, high occupancy rates for infirmary and intensive care beds and the need to guarantee a response to a demand that was exponential (in January and February 2021), by ensuring the mobilization of all health professionals and providing a response aligned with the demand for resources.

According to these guidelines, hospital establishments of the SNS must ensure prompt response to COVID-19 and guarantee the best possible balance of the various care responses, especially at the level of Intensive Care. To achieve this prioritization, health establishments:

a) upped their Contingency Plans to the maximum level and proceeded to their review and expansion, in order to maximize the response of the hospital capacity to the local, regional and national epidemiological situation, in articulation with the National Response Monitoring Committee in Intensive Care Medicine (CARNMI, Comissão de Acompanhamento da Resposta Nacional em Medicina Intensiva) and the respective Regional Health Administrations;

b) suspended the programmed non-urgent assistance activity that can be rerouted to reinforcing care to the critically ill patients, provided 
that such suspension, due to its nature or clinical priority, does not signify risk placing the patients' lives at risk, severely limiting their prognosis and/or limiting access to periodic or monitoring treatments (namely in the context of monitoring pregnancy), or worsening chronic or other diseases;

c) proceeded with the deferral of (normal or priority) scheduled surgical activity;

d) promoted the allocation of human resources for Intensive Care Medicine, in order to maximize the response capacity in this area, in accordance with the suspension and deferral of care activity carried out (subject to proposal by CARNMI and always in articulation with the clinical management of each unit).

Considering all of the above, regarding the terms of resource allocation, the Portuguese Government has given total priority to combating the pandemic, relegating to the background all other pathologies that need hospital follow-up. This fact has resulted in a high increase in mortality rates in Portugal (with cause of death established as pathologies other than infection by the SARS-CoV-2 virus).

In the accounting made by the National Statistics Institute (INE, Instituto Nacional de Estatística), between March $2^{\text {nd }}$ and December $27^{\text {th }}, 2020,99356$ deaths were recorded in Portugal, which represents an additional 12852 (compared to the average of the last five years). Of these, only $52 \%$ - (6677) - were caused by covid- 19 .

Monitoring of the remaining pathologies remains ongoing. The Portuguese Ministry of Health clarified that the Dispatch sent to hospitals does not order urgent or very priority surgery to be suspended and does not apply to hospitals such as the Portuguese Institute of Oncology (dedicated, exclusively, to the treatment of cancer patients). The Ministry of Health ensures that "the deferral of surgical activity will always be done through clinical evaluation and with the guarantee that there is no limitation of the patients' prognosis". The Ministry adds that the priority oncologic surgeries must occur up to 45 days after the indication for surgery, stressing that the order is in force until January $31^{\text {st }}$. According to this entity, "the dispatch does not apply to hospitals such as the IPO that, according to the healthcare network, are available to receive patients who require priority surgery during the period of application of the order". In addition, this pandemic had a special impact on some consolidated rights of patients, namely, on the maximum 
guaranteed response times, on free access and circulation in the SNS and on visiting rights.

\section{Maximum Guaranteed Response Times}

The Charter of Access Rights to Health Care (Carta dos Direitos de Acesso aos Cuidados de Saúde), applicable to patients of the SNS, determines that the user of the SNS is entitled not only to the provision of care in a time considered clinically acceptable for his health condition, but also the fulfilment of the maximum guaranteed response times (TMRG, in Portuguese, which are defined annually by ordinance of the Ministry of Health) for all types of care provided without urgency as well as the right to complain to the Health Regulatory Entity if the TMRGs are not met.

In Portugal, maximum guaranteed response times are defined by law. Law no. 15/2014, of March $21^{\text {st }}$, consolidated the legislation on the rights and duties of the user of health services, and was complemented by Ordinance no. 153/2017, of May $4^{\text {th }}$, which defines the maximum guaranteed response times in the SNS, depending on the clinical priority. However, according to information released by the Government, during the first wave of the pandemic, in May 2020, there was a very significant drop in the activity of the SNS due to the COVID-19 pandemic, which resulted in a decrease of primary health care responses, with a $3.9 \%$ drop in overall appointments (which corresponds to 300,000 consultations) and a decrease of $5.7 \%$ in hospital appointments (minus 180,000 consultations).

Concerning SNS scheduled surgeries, in the same period, there was a decrease of $5.3 \%$ (minus 9,000) and a general drop in emergency services amounted to a $11.5 \%$ reduction. Additionally, supplementary diagnosis tests had a decrease of $25 \%$ in some specialties (such as gastroenterology). Oncological surgery was reduced by $15 \%$ and the demand for emergency services dropped, on some of the registered days, by $50 \%$. SPO - Sociedade Portuguesa de Oncologia, the Portuguese association for Oncology - estimates an $80 \%$ reduction in cancer diagnoses (data from: Jornal Expresso, 11-05-2020).

The situation rapidly deteriorated in January 2021 . On the $13^{\text {th }}$ of January, Order no. 574-A/2021, determined, as we have already mentioned, that SNS hospital establishments up their Contingency Plans to 
the maximum level and suspend the programmed non-urgent activity. With this decision, and in accordance with the objective of maximizing the available capacity, it was necessary to suspend the programmed assistance activity (as long as it does not place the patient in a life threatening situation or serious damage, given his clinical priority).

At the end of December, more than 5000 patients were enrolled for cancer surgery. The Ministry of Health has been requested to and has since announced plans to reduce waiting lists, resorting to the private and social sectors, but it is too early to assess the practical reality and the eventual success of these plans?.

What is unquestionable at this point, according to the permanent updates of the National School of Public Health, is that between February 2020 and February 2021, the mortality in Portugal (not including deaths attributable to a SARS-COV-2 infection) was the highest of the last ten years.

\section{Free Access and Circulation Within the SNS}

In Portugal, the system of Free Access and Circulation of Users within the SNS, approved by Order no. 5911-B/2016, of May $3^{\text {rd }}$, allows the patient, together with the family doctor responsible for referral, to opt for any of the SNS hospital units where there is availability for the specialty consultation the patient requires. Referencing is done according to the patient's interest, according to geographical proximity criteria and considering the average response times in the institutions.

The right to free access and circulation was compromised with as the maximum level of Contingency Plans was instated. Currently, the health care offer receives almost daily updates, due to the need to open new wards and hospitals, which seek to support an excessive health care need. At the same time, many health professionals with specific training were allocated to other medical specialties, namely, in support platforms for intensive care and pulmonology. This reality has drastically altered the reality of the basic referral networks.

9 https://www.publico.pt/2021/02/10/sociedade/noticia/ministerio-saude-prepara-plano-recuperar-cirurgia-oncologica-ficou-1950159 


\section{Right to accompany a Patient and Visitation Rights}

In accordance with the Portuguese law on the rights and duties of the user of health services (Chapter III of Law no. 15/2014, of 21 March), the patient is entitled to be accompanied by a person of his/her choice, and this information must be provided upon admission by the service. Pregnant women admitted to a health facility are also awarded the right to be accompanied, during all stages of labour, by any person chosen by them.

This right is extended to hospitalized children, the disabled, people in a situation of dependency and people with an incurable disease in an advanced stage and in a final stage of life.

In cases where the clinical situation of the patient does not allow for him/her to freely choose a companion, the hospital must promote the right to be accompanied, and for this purpose may request the demonstration of family relationship between the patient and the companion.

Point 13 from The Charter for the Rights of Hospitalized Patients (DGS) states that the hospitalized patient has the right of visitation by his family and friends whenever he wishes (within the approved schedule), and provided that there is no contraindication. Institutions and professionals must facilitate and even encourage affective support that family members can provide to the patient. The most complicated family situations where there are conflicts between different family members and/or friends have to be discreetly and subtly considered by the professionals. Patients who do not have visits and feel isolated should have greater support from both health and volunteer staff who are properly prepared and trained. Inpatients who are unable to understand or make themselves understood are entitled to be accompanied by the person who usually cares for them and for whom there must be minimal conditions.

When the hospitalized person is not accompanied, the management of the health establishment must take care to provide any necessary personalized assistance, appropriate to the situation.

A patient is not allowed company to attend surgical interventions and other exams or treatments which, for their nature, may see their effectiveness and quality hindered by the presence of the companion, unless express authorization by the responsible clinician is given in these instances. In general, the right to be accompanied cannot compromise 
the technical conditions and requirements that medical care must comply with.

Health institutions, both public and private, define their visit regulations according to the dynamics of the services, providing that, as a rule, patients can always receive visits, fulfilling the requirements generically defined in those regulations.

In specific situations, such as end-of-life, the law itself clearly affirms the right to receive visitors as a transversal principle with reinforced value. This right to be accompanied and the right to receive visitors were both trimmed back dramatically during the pandemic. Some of these limitations were directly and objectively based on the needs for sanitary care provision and were carried out with strict respect for the recommendations of the General Directorate of Health. But limitations due to failures in the organization of services and the arbitrariness of the adopted measures, resulted in situations of profound loneliness and isolation, especially for vulnerable people.

Also concerning visitation rights, the pandemic imposed a set of extraordinary measures for residential homes for the elderly (ERPI), Integrated Continuous Care Units (UCCI) of the National Network of Integrated Continuous Care (RNCCI) and Social Assistance Establishments for the Support of Children, Youth, the Elderly or People with Disabilities. Initially, visits were unequivocally prohibited in such places, because health authorities believed that the measure was essential for containing spread of the infection. In May 2020, however, the DGS suspended this measure, setting forth the number and frequency of visits and stating the environmental conditions in which they should take place, thus providing a partial return to fundamental family and social interaction. During the very strong pandemic wave of January 2021, these limits on the right to visit returned. Although less stringen $\mathrm{t}^{10}$, the new restrictions were also tempered by a concurrent national vaccination campaign for users and employees in residential services.

10 For example, visits to elderly residential homes and elderly daycare activities were authorized during the state of emergency declared in January $15^{\text {th }}$. 


\section{Conclusion}

As stated at the outset: the state of emergency resulting from the pandemic, cannot legally create negative impacts on rights to life, personal integrity, personal identity, civil capacity and citizenship, the non-retroactivity of criminal law, the defence guarantees of the defendants and freedom of conscience and religion, although tempered by reasonable emergency restrictive measures. Considering all of the above, regarding the terms of resource allocation, the Portuguese Government has given total priority to combating the pandemic, relegating to the background all other pathologies that need hospital follow-up. Confronted with an inelastic supply of scarce health resources, guidelines have been implemented that, necessarily, entail restrictions impacting patient access to health care and exercise of their rights as patients, as a consequence of emergency pandemic measures. Nonetheless, such "restrictions" cannot legally jeopardize patients' life nor health. 
